\title{
Riverbed transformation as a result of a ferry crossing construction - case study
}

\author{
Anna Sosnowska ${ }^{1 *}$ \\ ${ }^{1}$ Department of Water Engineering and Hydraulics, Faculty of Building Services Hydro and Environmental Engineering, \\ Warsaw University of Technology, 20 Nowowiejska Str., 00-653 Warsaw, Poland
}

\begin{abstract}
Riverbed under the influence of natural and anthropogenic factors is constantly being transformed. The changes of the channel parameters related to natural phenomena are rarely dynamic. Contrarily it is in the case of human activity. The introduction of river engineering structures to the riverbed aims to quickly adapt the river to the requirements. If construction of such forms is designed taking account of natural conditions prevailing in the riverbed, then negative effects cannot be observed. The situation is different when the river's characteristics were not considered in the design process. The article discusses the changes that the riverbed has undergone due to its intensive contraction at the ferry crossing at $\mathrm{km} 488$ of Vistula, in Gassy. Current and archival aerial photographs were analyzed in terms of the transformation of the riverbed width, as well as the size of the mid-channel islands. The focus was concentrated on a section of the river $2 \mathrm{~km}$ above and $4 \mathrm{~km}$ below the ferry crossing. In particular, the parameters of the channel bar located directly below the narrowing and their change over the last decades were analyzed. Conclusions were drawn regarding the case study and recommendations for designing analogous solutions ensuing from the analysis were formulated.
\end{abstract}

\section{Introduction}

All fluvial processes that are responsible for the shape of river channel are dependent on two hydrodynamic features: flow of water and riverbed material movement. Between those media, depending on the energy level, processes of erosion or sedimentation occur. Contingent on the intensity of those processes, along big rivers, there can be distinguished three different zones: upstream, middle and downstream. Erosion dominates at the upstream part of the river, whilst sedimentation outweighs in the downstream zone. Middle section is the one where erosion and sedimentation intermingle. River morphology comprises many different characteristics of river channels. The most important are: vertical system, horizontal layout and cross-sections of the channel $[1,2]$. This article deals with the planform of river that can be assessed on the base of cartographic material.

Modern research studies of the horizontal layout of rivers are based not only on typical cartographic materials, which are traditional maps, but also on aerial or satellite imaging. Moreover, aerial photographs and orthophotomaps that are produced on their basis are considered to be the most useful tools for river morphology analysis, especially, shorelines and midchannel structures $[3,4,5]$.

The phenomena of riverbed transformations in natural, sandy rivers are difficult to describe. This is a result of the interchangeable character of hydro- and morphodynamics of the river. Configuration and morphology of mid-channel bars impact flow conditions. Whilst, changed hydrodynamics influence morphology of the riverbed [6].
Additional factor that can influence morphology or hydrodynamics of the river is human activity. The anthropogenic impact comprising river regulation can be very significant, especially locally, for confined river reaches.

In this case study an attempt was made to determine how human activity, which is represented here by the construction of a river ferry crossing, has influenced channel morphology. The analysis of intensive flow contraction in natural big river bases on cartographic material has not been widely studied yet.

\section{Case study}

The case study reach of Vistula is localized in the Middle Vistula, couple of kilometers upstream Warsaw. The analysis comprises $6 \mathrm{~km}$ of the river (from $\mathrm{km} 486$ to $\mathrm{km} 492$ of the Vistula). Localization of the case study reach is shown in Fig. 1. The middle part of the Vistula river has undergone some river engineering works in the past (1960's and 1970's), which indicates that it cannot be determined as a fully natural channel. However, the river training works have not been completed along the whole river, so there are some fragments of river that are not thoroughly covered with groynes or longitudinal dams and this concerns the case study section.

The discussed river reach is localized in the transition zone between two different types of river channel. In the north, downstream the examined section, in Warsaw city's boundaries, Vistula river and its flow are intensively limited by geological conditions and river training structures. Meanwhile, in the south and upstream

*Corresponding author: anna.sosnowska@pw.edu.pl 
the discussed section the river channel can be classified as mature and free-flowing. [7]

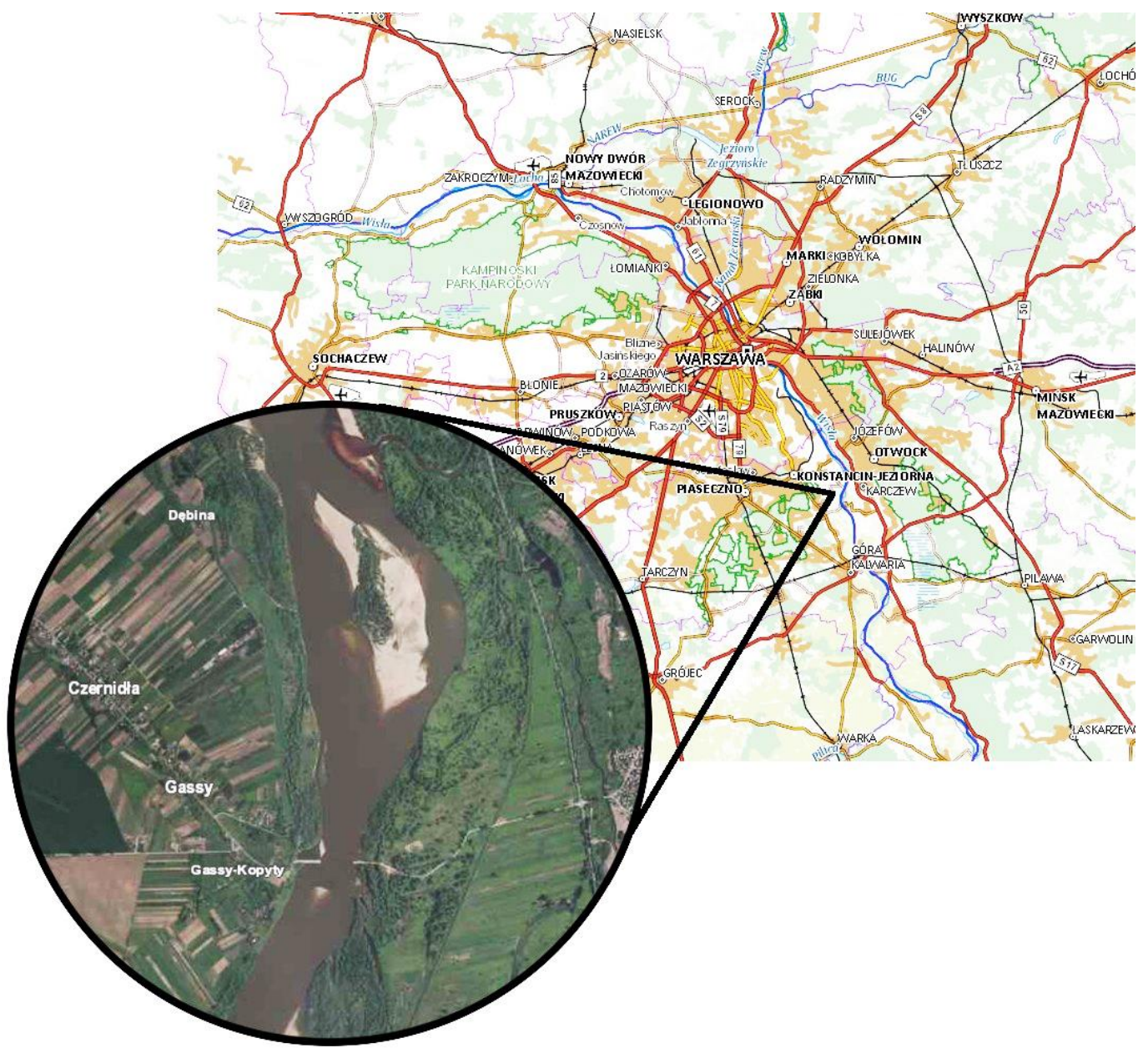

Fig. 1. Localization of the case study area [8]

The main focus is on the ferry crossing which is localized at $488 \mathrm{~km}$ of Vistula. This structure has been commissioned in 1981, but its impact on the river has begun couple of years earlier. The construction is visible at the aerial photographs from 1979. Initially it was built as a military construction. Now it is used as a car ferry crossing. It operates from April to November, depending on Vistula's stages.

The width of the channel at the crossing is around 190 $\mathrm{m}$, while the original channel width was about $460 \mathrm{~m}$. The construction of crossing caused flow contraction to about $40 \%$ of the initial value.

\subsection{Data and methods}

The analysis was based on aerial images of the discussed river reach that were taken in different time periods. Available materials were used to perform an analysis of the channel transformation and its pace in considered time interval.

Five series of photographs were examined. Specific dates of the surveys and hydrologic information from the nearest gauging station (Warszawa Nadwilanówka, at 504 $\mathrm{km}$ of Vistula) are given in the Table 1. Despite the fact that values of flows and stages may seem different from each other, it can be stated that the series of aerial photographs were taken in similar hydrologic conditions. According to [9] for the period between 1951 and 1990 the mean flow value (SQ) for Warszawa - Nadwilanówka gauging station equals $573( \pm 117) \mathrm{m}^{\wedge}-3 / \mathrm{s}$, while the low flow value (NQ) is $211( \pm 58) \mathrm{m}^{\wedge}-3 / \mathrm{s}$. This indicates that all the series of images were conducted in mean hydrological conditions. Difference in stage values between 1979 and 2003 indicates that the fluvial conditions at the discussed river reach have changed over those 24 years.

Table 1. Information about aerial photographs' series [10]

\begin{tabular}{|c|c|c|c|}
\hline Series & Date & Stage $[\mathbf{c m}]$ & Flow $\left[\mathbf{m}^{\mathbf{3}} / \mathbf{s}\right]$ \\
\hline 1959 & $13-$ Sep-1959 & $-*$ & $-*$ \\
\hline 1979 & $7-$-Oct-1979 & 127 & 338 \\
\hline 1984 & 31 -Oct-1984 & 143 & 373 \\
\hline 1997 & $8-$ Dec-1997 & 319 & 541 \\
\hline 2003 & $19-$ Sep-2003 & 192 & 193 \\
\hline
\end{tabular}

* data unavailable 
The photographs from each series were brought to one coordinate system and analyzed using GIS software. Features that were considered in all series were:

- Course of the left bank,

- Course of the right bank,

- Contours of channel bars,

- Area of the channel,

- Area of channel bars.

The comparison of all the shore lines is presented in Fig. 2.

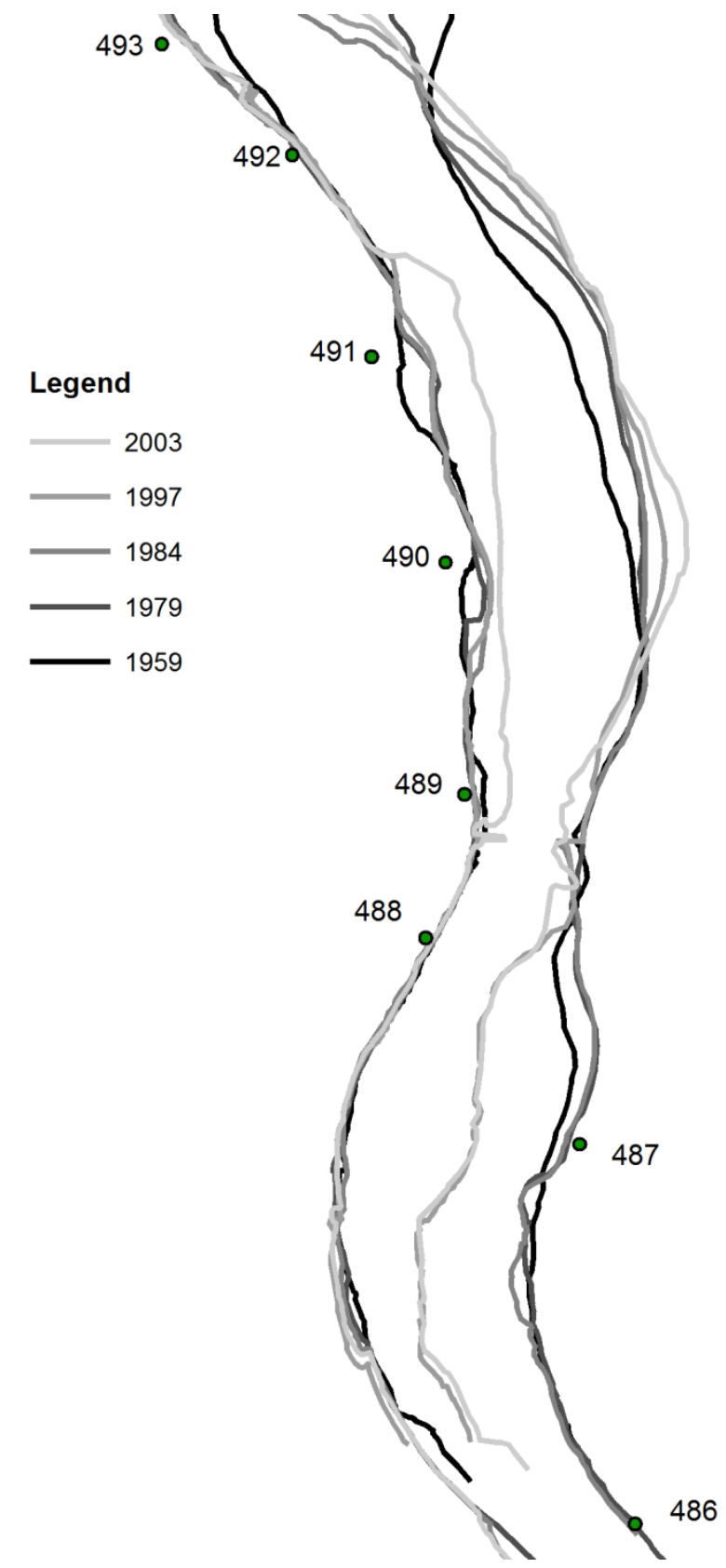

Fig. 2. Contour lines of channel banks

It is noticeable that since 1959 the left bank has moved toward the center of the channel, but only at limited length (along 2,5 km downstream the ferry crossing). In the upstream part of the discussed section the right bank has moved to the channel's center. It is a consequence of river regulation works and the commissioning of groynes in 60's and 70's. From the ferry crossing downstream, along the whole meander, the river has incised the right bank. At the end of the discussed river fragment, the right bank contour has again approached the channel's center.

\subsection{Area analysis}

Basing on banks' contours the total area of the channel in distinct years could be determined. Due to different water table stages for each photographic series, it was considered that the comparison of the total area of the channel would be significantly flawed.

Taking into account the possible error, the area of the bar located downstream the ferry crossing was calculated for each series of photographs (Table 2). It was assumed that it would be useful for the qualitative analysis.

Table 2. Area of the discussed bar

\begin{tabular}{|c|c|}
\hline Series & $\begin{array}{c}\text { Area of the bar downstream } \\
\text { the crossing }\left[\mathbf{m}^{2}\right]\end{array}$ \\
\hline 1959 & 0 \\
\hline 1979 & 152923 \\
\hline 1984 & 141802 \\
\hline 1997 & 120626 \\
\hline 2003 & 424984 \\
\hline
\end{tabular}

Despite the fact that the aerial images in distinct photographic series were taken during different water stages and the values presented in Table 2 can be flawed, it is certain that the area of the bar located downstream the ferry crossing is increasing. The structure has not existed in 1959. In the 80 's was about $150000 \mathrm{~m}^{\wedge} 2$ and now it is more than twice that bigger being a huge obstruction in the center of river channel. The process of building-up the bar downstream is visible in the Fig. 3.

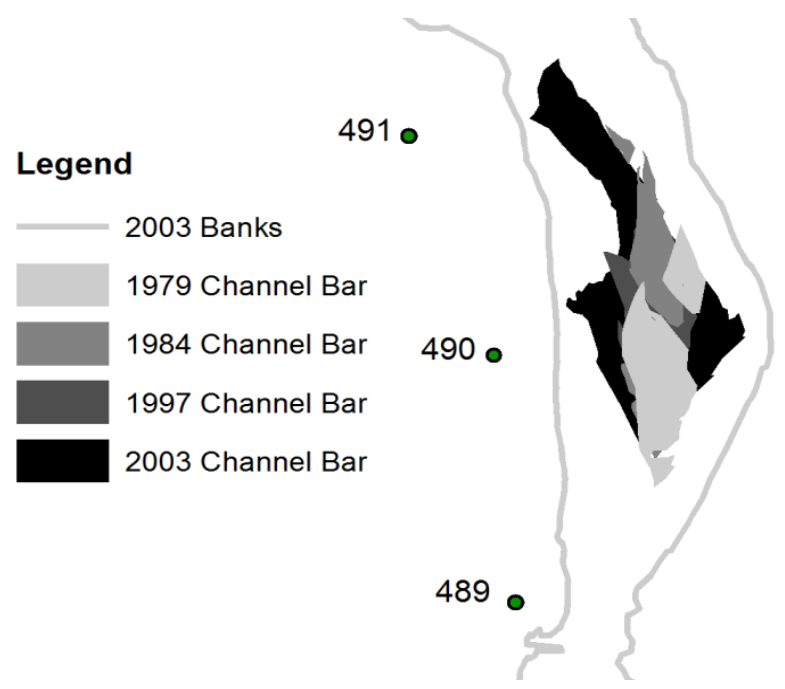

Fig. 3. Size of the channel bar downstream the crossing 


\subsection{Width analysis}

The investigation of the channel width was also conducted. It was based on the banks' contour lines and channel cross-sections. Widths were measured in
25 cross-sections that were distant from each other by 250 $\mathrm{m}$. The changes of the river channel widths in different years are shown on the graph (Fig. 4). There is also an indication of initial runs and meanders location along the discussed river section.

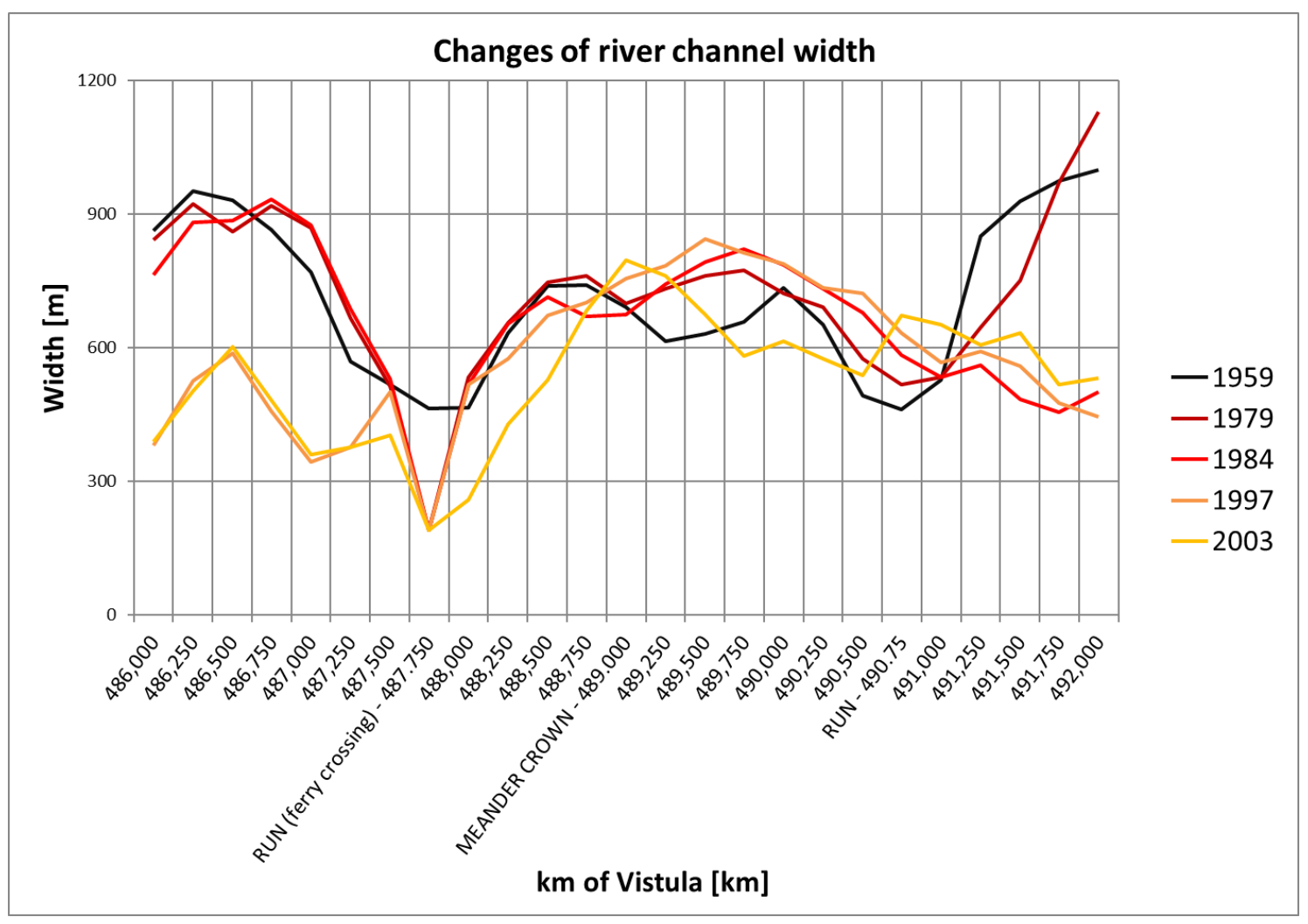

Fig. 4. Changes of river channel width in time

In 1959 the width of the channel was the smallest at the runs and the greatest at meanders. In addition, the channel was not the widest at the meander crown. After a ferry crossing construction the width of the channel at $\mathrm{km}$ 488 has decreased from over $460 \mathrm{~m}$ to $190 \mathrm{~m}$. This resulted in the changes of river shape parameters downstream. From 1979 the width of the channel at the meander downstream the ferry crossing has transformed, so that the widest cross-section has moved upstream. What is more, the river has also changed at the end of the discussed reach. For years 1984, 1997 and 2003 it is noticeable that channel downstream the second run is not widening to the same extent as it was in 1959 or 1979 . It seems that the river "has lost its pattern of runs and meanders" or it is starting to create a new pattern comprising couple of smaller meanders rather that one big. Basing on the Fig. 4, for 2003 there could be distinguished two small meanders - along km 488 - 490 and along 490 - 492 .

\subsection{Meander analysis}

Widths study has shown that there were significant changes of the channel geometry downstream the discussed ferry crossing. Therefore, it was considered that the analysis of the meander parameters was necessary. Two basic parameters were examined: radius of meander arch (R) and the length of meander (L). The changes of those dimensions in time are shown in Fig. 5.

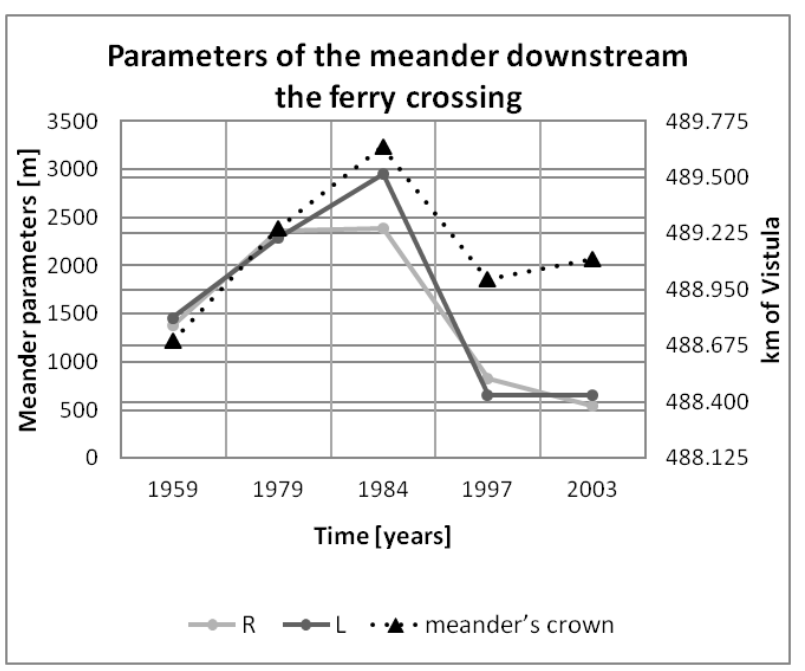

Fig. 5 Changes of parameters of the meander downstream the ferry crossing in time

The dimensions of the discussed meander have been increasing from 1959 until 1984. After that, both the radius and the length of the arch, have significantly decreased. What cannot be omitted here, is the fact that the measures for years 1997 and 2003 do not concern the 
same arch as in the previous years. It is due to the fact that the meander shape has been transformed. After 1997 it could only be described by an arch of a variable curvature.

Considering the course of the right bank along the meander an attempt was made to quantify the incision process. Distances between right bank lines for distinct years were measured and presented in Table 3. Dimension of incision was measured along black arrow on Fig. 6.

Table 3. Measurements of right bank incision

\begin{tabular}{|c|c|}
\hline Series & Distance [m] \\
\hline $1959-1979$ & 70 \\
\hline $1979-1984$ & 15 \\
\hline $1984-1997$ & 70 \\
\hline $1997-2003$ & 105 \\
\hline Total (1959-2003) & $\mathbf{2 6 0}$ \\
\hline
\end{tabular}

Measurements of the incision indicated that this process is progressing and the right bank of river channel along the meander is being constantly eroded. The total distance between right bank's contour in 1959 and 2003 was $260 \mathrm{~m}$, whilst the total width of the cross-section in 490 $\mathrm{km}$ of Vistula river in 1959 was around $730 \mathrm{~m}$. The channel has moved towards east of about $1 / 3$ of its initial width. The mean pace of the incision is about $5,9 \mathrm{~m}$ per year.

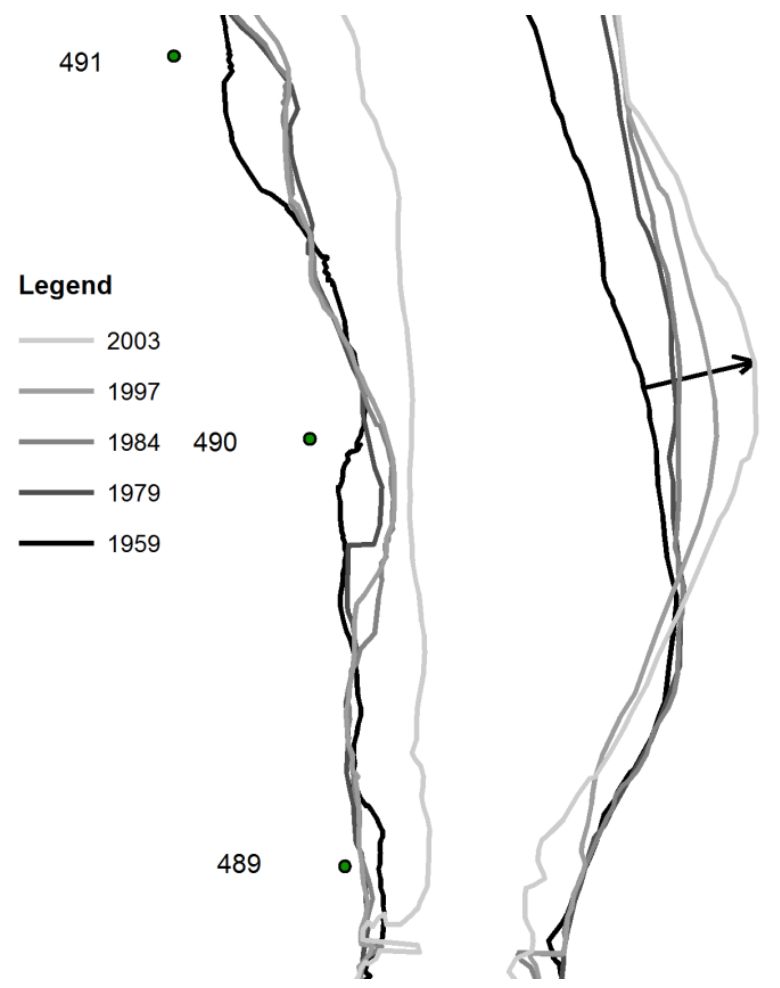

Fig. 6 Measurements of the right bank incision

\section{Summary}

The investigation of the channel parameters along the discussed section of Vistula river and their change in time show the impact of a ferry crossing construction at the riverbed. The analysis of river banks contours indicated that both banks have neared the channel's axis, with the exception of the right bank along the meander localized downstream the crossing. At this fragment the river has incised the right bank. The channel width analysis showed that after the construction of the crossing the river has changed its characteristics. The widest cross-section along the meander has moved upstream, towards the contracted cross-section and the channel has lost its "meander - run pattern" downstream the crossing.

A closer look at the meander localized directly downstream the introduced ferry crossing indicated that the geometry of the arch was also transformed comparing to its state in 1959. Character of the arch has changed from a constant curve to a variable curve. In addition, the meander's crown has moved upstream, towards the ferry crossing.

The most important change in the riverbed during the discussed period is the emergence of a huge channel bar downstream the contraction cross-section. In 1959, there were no significant bars in the channel, especially between 488 and $490 \mathrm{~km}$ of Vistula. Whilst in 2003, the bar has reached considerable dimensions, stretching along the river axis for about $1,5 \mathrm{~km}$. What is more, it was no longer a changeable outwash, but a regular island strengthened with plant growth. Resulting from that, the channel bar has become a serious obstruction for the river flow. This, consecutively, is the main reason of the right bank incision downstream the ferry crossing.

\section{Conclusion}

A detailed analysis of different river channel parameters conducted in this article showed that the introduction of a single construction into a river channel resulted in important morphological changes. New fluvial conditions connected to the dramatic contraction of the channel width at the ferry crossing (to $40 \%$ of initial value) implied significant changes downstream the discussed structure. The effect of a crossing construction was the most vivid along the meander localized directly downstream and it was twofold. On one hand, bank erosion of significant values can be observed in the river channel. Simultaneously, formation of mid-channel bar could be observed during the discussed time period.

Those two phenomena could be classified as consecutive. Firstly, the contraction of the river channel caused intensive sedimentation downstream the narrowing, in the expansion zone. Then, in different hydrodynamic conditions (lower discharges), an outwash became an obstacle causing flow separation, which led to bank erosion and the channel bar strengthening.

The above explanation leads to the conclusion that constructions causing such significant width contraction should not be designed as single objects in river channel. It would rather be recommended to erect accompanying 
hydro engineering structures as groynes or longitudinal dikes. Furthermore, the design of those objects should assure that the structure of the crossing itself is not endangered by different hydrodynamic conditions, but also prevent the river channel from being destroyed. In the case of "Gassy ferry crossing" there are two groynes accompanying the construction, one upstream and one downstream, both at the right bank. However, they only prevented the right beachhead from the destruction, not serving this function for the river channel.

In addition, the design of such structure as a ferry crossing should take into account the existing river regulation system. The heads of the crossing abutments should not project beyond the edge of the river's regulatory route. In the case study this condition is not fulfilled, as the width of regulatory route for Warsaw's Vistula is $220 \mathrm{~m}$, whilst the width of a ferry crossing is $190 \mathrm{~m}$.

Last but not least, when designing any structure that is contracting the flow of the river there should be taken great care about the localization of it. There will be different conditions considered for the structure localized at the run, than for a structure placed at the meander. The same applies to the localization of the crossing at the cross-section. Whether the crossing will be designed directly in the center of the cross-section or it will be set aside, there will be different circumstances created by this structure.

\section{References}

1. J. Żelazo, Z. Popek, Podstawy renaturyzacji rzek (Wydawnictwo SGGW, Warszawa, 2014)

2. J. Wołoszyn, W. Czamara, R. Eliasiewicz, J. Krężel, Regulacja rzek i potoków (Wydawnictwo Akademii Rolniczej we Wrocławiu, Wrocław, 1994)

3. M. Witek, J. Jeziorska, T, Niedzielski, Possibilities of using unmanned air photogrammetry to identify anthropogenic transformations in river channel, Landform Analysis 24, 115-126 (2013)

4. J. Forysiak, The application of aerial photo analysis to reconstruct anabranching system of middle part of the Warta river valley, Landform Analysis 13, 13-18 (2010)

5. T. Falkowski, P. Ostrowski, Morphogenesis of the Vistula river valley floodplain in the vicinity of Magnuszew (middle course) estimation with usage of aero and satellite photographs, Infrastructure and Ecology of Rural Areas 9, 89-100 (2010)

6. N. Claude, S. Rodrigues, V. Bustillo, J.-G. Breheret, P. Tassi, and P. Juge, Interactions between flow structure and morphodynamic of bars in a channel expansion/contraction, Water Resources Research 50, 2850-2873 (2014)

7. A. Kałmykow-Piwińska, T. Falkowski, Assessment of the channel morphologic stability in the base of archival cartographic and photogrammetric data in
GIS environment, Sci. Rev. Eng. Env. Sci 58, 251262 (2012)

8. www.geoportal.gov.pl

9. B. Fal, E. Bogdanowicz, Characteristic flow values of the main Polish rivers in the years 1951-1990 : a new publication by the IMGW, Gospodarka Wodna 9, 178-178 (1998)

10. L. Kuc, Long-term variability of the hydrological regime of the Vistula River in Warsaw, Politechnika Warszawska (2012) 